\title{
Correction to: Machine learning based tool for identifying errors in CAD to GIS converted data
}

Mohamed Badhrudeen, Nalin Naranjo, Ali Movahedi

and Sybil Derrible

\section{Correction to:}

Chapter "Machine learning based tool for identifying errors in CAD to GIS converted data" in: C. Ha-Minh et al. (eds.), CIGOS 2019, Innovation for Sustainable Infrastructure, Lecture Notes in Civil Engineering 54, https://doi.org/10.1007/978-981-15-0802-8_190

The original version of this chapter was inadvertently published with incorrect Author name as "Ali Mohavedi". This has now been corrected as "Ali Movahedi" in the chapter "Machine learning based tool for identifying errors in CAD to GIS converted data." 